\title{
Single-guidewire double-tip cannulation for difficult biliary access: the DTC technique
}

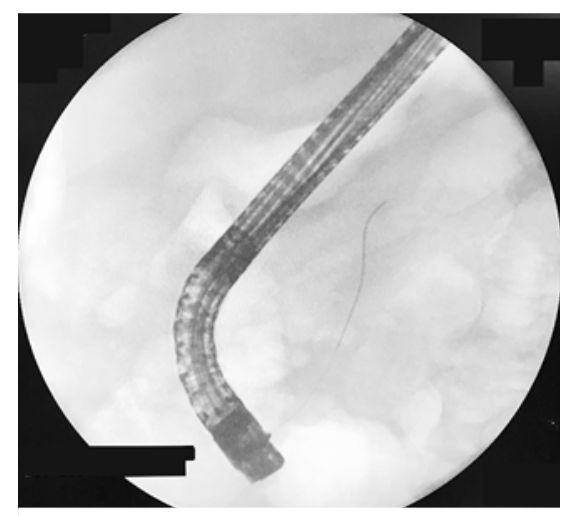

> Fig. 1 First guidewire tip inside the main pancreatic duct.

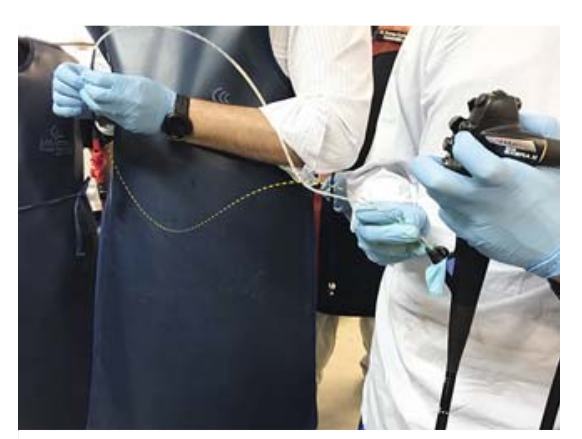

Fig. 2 Double-tip guidewire loop, with the second tip inside the sphincterotome.

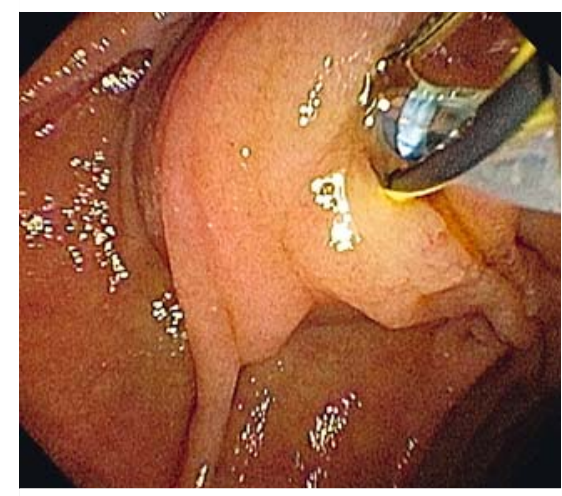

- Fig. 3 Sphincterotome reinsertion to perform deep biliary cannulation.
The double-guidewire technique (DGT) for difficult biliary cannulation was first described by Dumonceau et al. in 1998 [1]. Over recent years, DGT has become an important advanced technique after unsuccessful standard retrograde cannulation (guidewire-assisted or contrast-assisted), especially when unintentional pancreatic duct cannulation occurs [2]. The success rate of DGT for biliary cannulation in randomized controlled trials ranges from $66.6 \%$ to $92.5 \%$ [3]. We describe a similar alternative to DGT using a single guidewire with two hydrophilic tips.

A 75-year-old man was admitted to the hospital with non-severe pancreatitis. Physical examination was unremarkable except for mild jaundice. Abdominal ultrasound showed gallstones inside the common bile duct, and laboratory studies revealed total bilirubin of $4.8 \mathrm{mg} / \mathrm{dL}$ (direct bilirubin $3.5 \mathrm{mg} / \mathrm{dL}$ ). After resolution of the pancreatitis, the patient was referred for endoscopic retrograde cholangiopancreatography with stone extraction.
During the procedure, we encountered difficult biliary access, with three pancreatic duct cannulations ( $\mathbf{F i g} \mathbf{1}$ ). In our unit, we routinely employ sphincterotome-assisted guidewire cannulation. In this case, we used a Hydra Jagwire (Boston Scientific, Marlborough, Massachusetts, USA), which offers two hydrophilic tips. After the third pancreatic duct cannulation, the first tip was kept inside the main pancreatic duct. We removed the sphincterotome, reinserted the second tip through its guidewire channel ( $\triangleright$ Fig. 2 ), and successfully performed biliary cannulation similarly to DGT ( $\bullet$ Fig. 3, $\triangleright$ Video 1). Finally, we performed the sphincterotomy and balloon sweeping.

At follow-up, the patient presented neither abdominal pain nor hyperamylasemia and was referred to a gastrointestinal surgeon for laparoscopic cholecystectomy.

DGT for difficult biliary access is effective and widespread but carries high related costs owing to the need for an extra guidewire. The single-guidewire doubletip cannulation (DTC) technique is as ef-

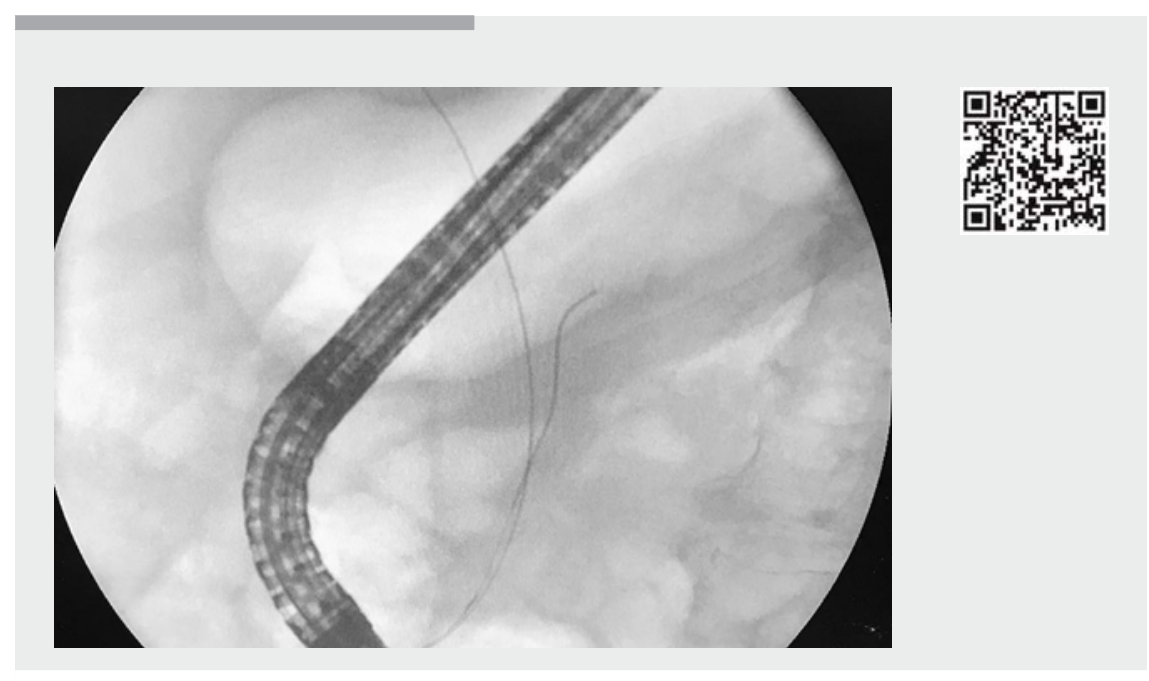

$\checkmark$ Video 1 The single-guidewire double-tip cannulation technique for difficult biliary access. 
fective and safe as DGT but has no additional costs. Employment of the DTC technique on a regular basis may result in a more convenient and less costly approach to difficult biliary access [4].

Endoscopy_UCTN_Code_TTT_1AR_2AK

\section{Competing interests}

None

The authors

Tomazo P. Franzini, Rodrigo S. P. Rocha, Hugo G. Guedes, Vitor O. Brunaldi, Juan P. R. Serrano, Antônio C. Madruga Neto, Eduardo

\section{G. H. Moura}

Gastrointestinal Endoscopy Unit, Hospital das Clínicas, University of São Paulo Medical School, São Paulo, Brazil
Corresponding author

\section{Tomazo Franzini, MD, PhD}

Gastrointestinal Endoscopy Unit, Hospital das Clínicas, University of Sao Paulo Medical School, Dr. Arnaldo Av, 455, São Paulo, 01246-903, Brazil

tomazof@uol.com.br

\section{References}

[1] Dumonceau JM, Devière J, Cremer M. A new method of achieving deep cannulation of the common bile duct during endoscopic retrograde cholangiopancreatography. Endoscopy 1998; 30: S80

[2] Liao WC, Angsuwatcharakon P, Isayama H et al. International consensus recommendations for difficult biliary access. Gastroint Endosc 2017; 85: 295 - 304

[3] Tse F, Yuan Y, Moayyedi P et al. Doubleguidewire technique in difficult biliary cannulation for the prevention of post-ERCP pancreatitis: a systematic review and metaanalysis. Endoscopy 2017; 49: 15- 26

[4] Yang MJ, Hwang JC, Yoo BM et al. Wireguided cannulation over a pancreatic stent versus double guidewire technique in patients with difficult biliary cannulation. BMC Gastroenterology 2015; 15: 150

\section{Bibliography}

DOI https://doi.org/10.1055/a-0624-1280

Published online: 12.6.2018

Endoscopy 2018; 50: E212-E213

(c) Georg Thieme Verlag KG

Stuttgart · New York

ISSN 0013-726X

\section{ENDOSCOPY E-VIDEOS}

https://eref.thieme.de/e-videos

回回 Endoscopy E-Videos is a free access online section, reporting 口if: on interesting cases and new techniques in gastroenterological endoscopy. All papers include a high quality video and all contributions are freely accessible online.

This section has its own submission website at https://mc.manuscriptcentral.com/e-videos 